\title{
CARACTERÍSTICAS AGRONÔMICAS DO MILHO SOB ARRANJOS ESPACIAIS E DENSIDADES DE PLANTAS EM REGIÃO DE CERRADO
}

\author{
João Paulo Ferreira ${ }^{1}$, Ricardo Antonio Ferreira Rodrigues ${ }^{2}$, Flavio Hiroshi Kaneko ${ }^{3}$, \\ Claudinei Kappes ${ }^{4}$, Marcelo Valentini Arf ${ }^{5}$, Renato Jaqueto Goés ${ }^{1}$
}

\footnotetext{
${ }^{1}$ Doutorando em Agronomia - UNESP Campus de Ilha Solteira (SP).

${ }^{2}$ Docente do DEFERS - UNESP Campus de Ilha Solteira (SP).

${ }^{3}$ Professor EBTT do IFMS Campus de Nova Andradina (MS).

${ }^{4}$ Doutor Pesquisador em Sistema de Produção e Fertilidade do Solo - PMA, Fundação MT.

${ }^{5}$ Doutor Pesquisador e consultor em Agricultura de Precisão - Fundação Chapadão MS.
}

RESUMO: A redução no espaçamento entrelinhas e a adoção de maiores densidades de plantas têm sido utilizadas por muitos pesquisadores, tendo em vista que os novos genótipos introduzidos no mercado são mais produtivos, com arquitetura de plantas de porte mais baixo e folhas eretas, com melhor aproveitamento de luz, água e nutrientes, proporcionando um possível aumento de produtividade da cultura. $\mathrm{O}$ trabalho foi desenvolvido na Faculdade de Engenharia de Ilha Solteira - UNESP, na fazenda de ensino e pesquisa (FEPE), localizado no município de Selvíria - MS, em Latossolo Vermelho Distrófico, textura argilosa. O delineamento experimental foi em blocos casualizados com quatro repetições, em esquema fatorial (5x2x2), sendo cinco populações (40.000; 55.000; 70.000; 85.000 e

100.000 plantas $\left.\mathrm{ha}^{-1}\right)$, com dois espaçamentos entrelinhas $(0,45$ e 0,90 metros $)$ e dois sistemas de cultivo (plantio direto e convencional). O hibrido simples de milho utilizado foi o Monsanto DBK 390, com arquitetura moderna e folhas semieretas. Não houve efeito significativo para as características agronômicas avaliadas em relação ao espaçamento de 0,45 e $0,90 \mathrm{~m}$ entre linha. Houve ajuste linear da população de plantas para os componentes de acamamento e quebramento de grãos, altura de plantas, inserção de espiga, diâmetro de colmos, diâmetro de espiga, diâmetro de sabugo, comprimento de grãos. O aumento da densidade de plantas apresentou ajuste linear para a produtividade de grãos onde na população de 100 mil plantas ha ${ }^{-1}$ foi de $10.410 \mathrm{~kg} \mathrm{ha}^{-1}$.

Palavras-chave: Espaçamento entrelinhas. População de plantas. Produtividade de grãos.

\section{SPATIAL ARRANGEMENT AND PLANT DENSITIES IN AGRONOMIC TRAITS CORN IN REGION OF SAVANNAH}

\begin{abstract}
The reduction in spacing and the adoption of higher plant densities has been used by many researchers as well as farmers, given that the new genotypes introduced to the business agricultural market are more productive, with architecture of plants and lower-sized upright leaves, with better use of light, water and nutrients, justifying a possible increase in crop yield. The study was conducted in the Selvíria - MS in oxisol, clay texture. The experimental design was a randomized complete block with treatments arranged in a

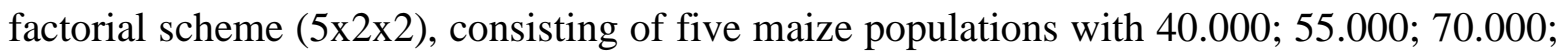

Cultura Agronômica, Ilha Solteira, v.24, n.1, p.27-44, 2015 
85.000 and 100.000 plants ha ${ }^{-1}$, with spacings of 45 and 90 meters between rows and two soil system, (no-tillage and conventional), with four replications was used hybrid corn DBK 390. There was no significant effect on the characteristics evaluated in relation to the spacing of $0,45 \mathrm{~m}$ between $0,90 \mathrm{~m}$ and linear fit. There was a linear fit between the plant population to the components of lodging and breakage of grain, plant height, cob insertion, stalk diameter, cob diameter, length of grain. The increase in plant density showed a linear fit for grain yield where the population of 100.000 plants ha ${ }^{-1}$ was $10.410 \mathrm{~kg} \mathrm{ha}^{-1}$.

Key words: Spacing rows. Plant population. Grain yield.

\section{INTRODUÇÃO}

O milho (Zea mays L.) é uma planta da família Poaceae, originária da América Central, sendo cultivada em praticamente todas as regiões do mundo, nos hemisférios norte e sul, em climas úmidos e regiões secas. Trata-se de um alimento rico em carboidratos, considerado como energético; é também fonte de óleo, fibras, vitaminas E, B1, B2 e ácido pantotênico, além de alguns minerais, como o fósforo e o potássio (MATOS et al., 2006). Em função de seu potencial produtivo, composição química e valor nutritivo, o milho constitui-se em um dos mais importantes cereais cultivados e consumidos no mundo. Devido à sua multiplicidade de aplicações, quer na alimentação humana quer na alimentação animal, assume relevante papel socioeconômico, além de constituir-se em indispensável matériaprima impulsionadora de diversificados complexos agroindustriais (FANCELLI; DOURADO NETO, 2000).

Em contraste com a produção total, que é a terceira do mundo e representa $6 \%$ da oferta mundial, a produtividade média nacional é muito baixo quando comparado aos valores superiores a $15.000 \mathrm{~kg} \mathrm{ha}^{-1}$ obtidos por Argenta et al. (2003), Forsthofer (2004) e por Sangoi et al. (2003) em trabalhos de pesquisa conduzidos nos Estados do Rio Grande do Sul e de Santa Catarina, ou a produtividade de 10.000 a $12.000 \mathrm{~kg} \mathrm{ha}^{-1}$ registrados em lavouras comerciais conduzidas sob alto nível tecnológico no Estado do Paraná. Carvalho (2007) afirma que algumas lavouras brasileiras chegaram a ultrapassar os valores médios de produtividade obtido pelos Estados Unidos na safra 2005, que foi de $9.947 \mathrm{~kg} \mathrm{ha}^{-1}$. De modo geral, a baixa produtividade de grãos das lavouras de milho no Brasil ocorre em função de uma densidade inadequada de plantas por unidade de área, além de fatores ligados principalmente à fertilidade do solo e ao arranjo espacial de plantas (FANCELLI; DOURADO NETO, 2004).

Para minimizar a competitividade de plantas de milho na linha de semeadura, tem se utilizado a redução do espaçamento entre as linhas, o que permite melhor arranjo espacial de plantas, aumentando a eficiência na interceptação da luz (FLÉNET et al., 1996), decorrente do aumento da produção fotossintética líquida (BULLOCK; NIELSEN; NYQUIST, 1988), especialmente em altas densidades populacionais (ALVAREZ; VON PINHO; BORGES, 2006; SANGOI; SILVA, 2005; SHIOGA, 2005)

A adoção do espaçamento reduzido e da maior densidade de plantas na cultura do 
milho já vêm sendo estudado, há muito tempo, porém apenas recentemente vem sendo utilizada de forma mais ampla pelos agricultores. Resultados de ensaios conduzidos nas regiões Sul, Sudeste e Centro Oeste do Brasil relatam ganhos de produtividade de grãos de até $14 \%$ com a adoção desta prática (VILARINHO, 2005). No Brasil, sistemas agrícolas irrigados que utilizam alto investimento têm registrado resultados satisfatórios em produtividade de grãos pela adoção de espaçamentos de 60 a $70 \mathrm{~cm}$ entre as linhas e maiores populações de plantas por unidade de área. Murphy et al. (1996) consideram a utilização do espaçamento reduzido como importante prática cultural na determinação da produtividade de grãos do milho.

A redução do espaçamento entre as linhas propicia distribuição mais uniforme entre as plantas na área de cultivo. De acordo com Palhares (2003), isso reduz a competição pelos recursos do ambiente, otimizando a sua utilização. $\mathrm{O}$ arranjo espacial mais favorável de plantas por área devido à aproximação das linhas estimula as taxas de crescimento da cultura no início de seu ciclo, incrementa a interceptação da luz incidente no dossel e aumenta a eficiência de seu uso. O desenvolvimento antecipado da cultura, além de aumentar a produtividade de grãos pode tornar a cultura mais resistente a possíveis estresses ambientais e ataques de pragas e doenças que possam acontecer no futuro (NUMMER FILHO; HENTSCHKE, 2006), aumenta também a competitividade com as plantas daninhas (PAES; ZITO, 2006; TEASDALE, 1995), reduzindo a dependência de uso de herbicidas (PAES; ZITO, 2006). Diante disso, o trabalho teve como objetivo verificar os efeitos de densidades populacionais em dois arranjos espaciais sobre as características agronômicas e produtividade de grãos de milho.

\section{MATERIAL E MÉTODOS}

O trabalho foi realizado em área sob irrigação por pivô central no período de primavera/verão no ano agrícola de 2010/2011 em área experimental pertencente UNESP, Câmpus de Ilha Solteira, localizada no município de Selvíria (MS), com as coordenadas geográficas aproximadas de $51^{\circ} 22^{\prime}$ ' Oeste de Greenwich, 20 $22^{\prime}$ Sul e 335 metros de altitude. O solo da localidade é um Latossolo Vermelho Distrófico, textura argilosa, de acordo com a classificação da Embrapa (2006), sendo a precipitação média anual local de $1.370 \mathrm{~mm}$, com temperatura e umidade do ar (médias anuais) de $23,5^{\circ} \mathrm{C}, 70$ a $80 \%$, respectivamente. Na figura 1, estão dispostas as médias da distribuição de precipitação pluvial, umidade relativa do ar, evapotranspiração potencial, temperatura máxima, média e mínima do ar durante o experimento.

O delineamento experimental foi o de blocos casualizados com os tratamentos dispostos em esquema fatorial $(5 \times 2 \times 2)$, constituídos de cinco populações de milho (40.000; $55.000 ; 70.000 ; 85.000$ e 100.000 plantas ha $\left.^{-1}\right)$, dois espaçamentos $(0,45$ e 0,90 metros entrelinhas), dois sistema de produção (plantio direto e cultivo convencional), com quatro repetições, perfazendo um total de 80 parcelas. A parcela experimental para análise constituiu-se de 2 linhas centrais de 5 metros de comprimento no espaçamento de $0,90 \mathrm{~m}$, com área útil de $9 \mathrm{~m}^{2}$, e 4 linhas centrais de 5 metros de comprimento no espaçamento de

Cultura Agronômica, Ilha Solteira, v.24, n.1, p.27-44, 2015 
0,45 m, sendo também de $9 \mathrm{~m}^{2}$ de área útil. Na tabela 1, está indicado o número de estande populacional pretendido no experimento.

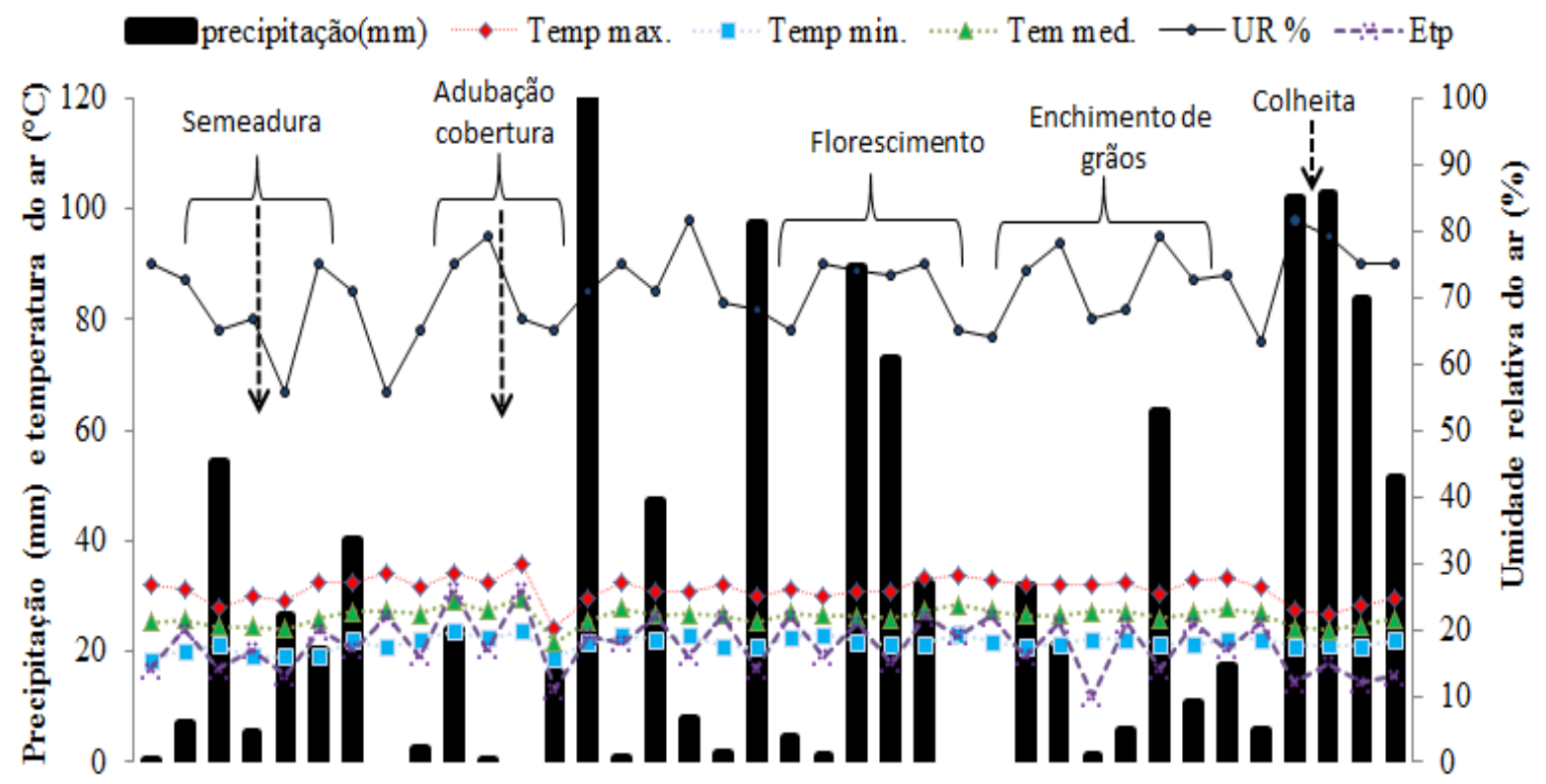

$\begin{array}{llllllllllllllllllllll}1-10 & 10-20 & 20-30 & 1-10 & 10-20 & 20-31 & 1-10 & 10-20 & 20-31 & 1-10 & 10-20 & 20-28 & 1-10 & 10-20 & 20-31 & 1-10 & 10-20\end{array}$

Nov Nov Nov Dez Dez Dez Jan Jan Jan Fev Fev Fev Mar Mar Mar Abr Abr

Figura 1. Distribuição das variáveis climáticas durante a condução do experimento: Precipitação pluvial (mm), evapotranspiração potencial, temperatura do ar e umidade relativa (\%). Selvíria-MS - Período primavera/verão de 2010/2011.

Fonte: Ciiagro (2011).

Tabela 1. Número de plantas em metro linear e equidistância entre plantas nos arranjos espaciais de 0,45 e 0,90 metros entrelinha.

\begin{tabular}{cccccc}
\hline & \multicolumn{5}{c}{ População (plantas ha' $\left.{ }^{-1}\right)$} \\
\cline { 2 - 6 } Espaçamento $(\mathbf{m})$ & 40.000 & 55.000 & 70.000 & 85.0000 & 100.000 \\
\cline { 2 - 6 } & \multicolumn{5}{c}{ Numero de plantas em metro linear } \\
\cline { 2 - 6 } $0,45 \mathrm{~m}$ & 1,8 & 2,47 & 3,15 & 3,82 & 4,50 \\
$0,90 \mathrm{~m}$ & 3,6 & 4,94 & 6,30 & 7,64 & 9,00 \\
\hline \multirow{2}{*}{$0,45 \mathrm{~m}$} & \multicolumn{7}{c}{ Equidistância entre plantas (em metros) } \\
\cline { 2 - 6 } $0,90 \mathrm{~m}$ & 0,55 & 0,40 & 0,32 & 0,26 & 0,22 \\
& 0,27 & 0,20 & 0,15 & 0,13 & 0,11 \\
\hline
\end{tabular}

Antes da semeadura, no ano agrícola de 2010/2011, a área de sob sistema plantio direto e cultivo convencional recebeu aplicação de herbicida (glyphosate - $1560 \mathrm{~g} \mathrm{ha}^{-1}$ do i.a.), aplicado no dia 15/10/2010 na dose de 5,0 $\mathrm{L} \mathrm{ha}^{-1}$ do produto comercial, com o objetivo de dessecar as plantas remanescentes e eventuais plantas daninhas da área. Na área de sistema convencional, houve o revolvimento do solo, utilizando grade pesada para incorporação de restos de culturas anteriores e em seguida, uma passada de grade leve para destorroamento e nivelamento da área experimental. O hibrido simples utilizado foi o DKB 390 da Monsanto, sendo este com tecnologia Bt Yieldgard®, apresentando supressão contra o ataque das principais pragas da cultura do milho: Lagarta-do-cartucho, lagarta-da-espiga e 
broca do colmo.

O milho foi semeado manualmente para alocar as populações pré-definidas pelos respectivos tratamentos (Tabela 1), sendo semeado no dia 18/11/2010, utilizando matracas e respeitando as distâncias entre as sementes na linha de semeadura nos respectivos espaçamentos, sendo feito apenas o sulco mecanicamente para marcar as linhas de semeadura e para efetuar a adubação química de base estabelecida pela análise de solo no local. Para marcar as linhas de semeadura e adubação, foi utilizada uma semeadora de precisão a vácuo, com o uso de haste sulcadora "botinha".

A adubação química básica no sulco de semeadura foi baseada na analise de solo nas profundidades de 0 - 0,10 e 0,10 - 0,20 metros em ambos os sistemas de preparo (Tabela 2), e foi constituída de $400 \mathrm{~kg} \mathrm{ha}^{-1}$ da fórmula 08-28-16 (1\% Ca; 2\% S; 0,3\% Zn). Na adubação de cobertura, foram aplicados $90 \mathrm{~kg}$ ha-1 de nitrogênio na forma de ureia, no estádio fenológico de 7 folhas (V-7) sendo realizado no dia 23/12/2010. As doses foram calculadas de acordo com as características químicas iniciais do solo no local (Tabela 2) e levando-se em consideração a faixa de produtividade esperada $\left(10-12 \mathrm{t} \mathrm{ha}^{-1}\right)$ e as recomendações do Boletim técnico 100, de acordo com Raij et al. (1997). Anteriormente, na área de plantio direto, a cultura antecessora foi o feijoeiro em sistema de sucessão com outras culturas como a soja e milho. Sendo que nesta área, estava sendo utilizado o sistema de plantio direto há aproximadamente 7 anos.

Tabela 2. Analise química inicial do solo na camada de $0,0-0,10$ e $0,10-0,20$ metros de profundidade em sistema plantio direta (PD) e sistema convencional (PC). Selvíria, 2010.

\begin{tabular}{lllllllllll}
\hline Ano & P resina & M.O. & $\mathbf{p H}$ & $\mathbf{K}$ & $\mathbf{C a}$ & $\mathbf{M g}$ & $\mathbf{H}+\mathbf{A l}$ & $\mathbf{S . B .}$ & $\mathbf{C T C}$ & $\mathbf{V}$ \\
\hline Prof. (m) & $\mathrm{mg} \mathrm{dm}^{-3}$ & $\mathrm{~g} \mathrm{dm}^{-3}$ & $\mathrm{CaCl}_{2}$ & -------------- & $\mathrm{mmol}_{\mathrm{c}} \mathrm{dm}^{-3}$ & ----------- & $\%$ \\
\hline PD 0-0,10 & 70 & 22 & 6,2 & 2,0 & 25 & 16 & 16 & 43,0 & 59,0 & 73 \\
PD 0,10-0,20 & 20 & 19 & 6,1 & 1,6 & 24 & 17 & 15 & 42,6 & 58,6 & 71 \\
\hline PC 0-0,10 & 47 & 20 & 5,8 & 3,8 & 22 & 13 & 20 & 38,8 & 58,8 & 66 \\
PC 0,10-0,20 & 29 & 20 & 5,4 & 2,3 & 18 & 11 & 25 & 31,3 & 56,3 & 56 \\
\hline
\end{tabular}

Método de análise do Instituto Agronômico de Campinas (IAC). Laboratório de Fertilidade do Solo - Unesp, Ilha Solteira

O controle de plantas daninhas foi realizado em pós-emergência nos dias 17/12/2010, quando as plantas de milho estavam com 6 a 7 folhas completamente desenvolvidas, com a aplicação do herbicida Tembotriona $\left(420 \mathrm{~g} \mathrm{~L}^{-1}\right.$ do i.a. $+783 \mathrm{~g} \mathrm{~L}^{-1}$ de ingrediente inerte) na dosagem de 1,0 $\mathrm{L} \mathrm{ha}^{-1}$ e Atrazina (500 $\mathrm{g} \mathrm{L}^{-1}$ de i.a) na dosagem de 2,0 $\mathrm{L} \mathrm{ha}^{-1}$ com objetivo de controlar gramíneas e plantas de folhas largas.

A colheita foi realizada nos dias 05/04/2011 e 06/04/2011, correspondendo ao ciclo de 130 dias, observando regularidade do ciclo pela característica do hibrido utilizado. Foram analisadas as características agronômicas da planta, tais como: Acamamento e quebramento de planta, considerada acamada e quebrada com ângulo da base da planta em relação ao solo menor que $45^{\circ}$ graus. A altura média de plantas, de inserção de espiga, diâmetro basal de colmo foram avaliadas em pleno florescimento tomadas como padrão 10 plantas em duas fileiras, sendo que para a altura média de planta foi mensurada a distancia da base da planta

Cultura Agronômica, Ilha Solteira, v.24, n.1, p.27-44, 2015 
até a inserção do pendão e na inserção de espiga foram mensuradas na base da planta até a inserção da espiga. $\mathrm{O}$ diâmetro de colmo, foi medido no $2^{\circ}$ internódio a partir da base da planta. $\mathrm{Na}$ análise de diâmetro de espiga, sabugo, comprimento da espiga, comprimento de grãos, numero de fileira de grãos e massa de cem grãos, foram avaliados no momento da colheita da produtividade de grãos separando-se dez espigas por tratamento para tais análises. Na produtividade de grãos, foram coletadas a duas linhas centrais de 0,90 metros e três linhas centrais de 0,45 metros onde foi realizada a debulha e pesagem dos grãos oriundos de todas as espigas colhidas na área útil das parcelas, sendo convertido para $\mathrm{kg} \mathrm{ha}^{-1}$ e corrigido para $130 \mathrm{~g} \mathrm{~kg}^{-1}$ de teor de água (base úmida). A análise de prolificidade foi realizada no momento da contagem da população final de plantas, sendo contabilizado nas duas fileiras centrais no espaçamento de 0,90 em três fileiras centrais no espaçamento de 0,45 metros, contabilizando o número de plantas com pelo menos duas espigas nos respectivos espaçamentos. As médias entre sistema de cultivo e espaçamentos foram comparadas pelo do teste Tukey a $5 \%$ e $1 \%$ de probabilidade e as populações de plantas pela análise de regressão. $\mathrm{Na}$ análise estatística de acamamento e quebramento de planta, os resultados foram transformados em $\sqrt{ } \mathrm{x}+0,5$, para atender aos pressupostos básicos da análise de variância (ANOVA). Os dados foram analisados com o auxilio do programa estatístico SISVAR (FERREIRA, 2000).

\section{RESULTADOS E DISCUSSÃO}

Na Tabela 3 estão apresentados os dados de porcentagem de acamamento e quebramento de plantas, altura média de plantas, altura média de inserção de espiga principal e diâmetro basal de colmos. Nesses resultados, não houve efeito significativo para sistema de cultivo para acamamento e quebramento de plantas, altura de plantas e para inserção da espiga, havendo apenas efeito significativo para diâmetro basal de colmos onde se observou maior diâmetro de colmo e de espiga no sistema de cultivo convencional. Em relação aos espaçamentos, observou-se que na avaliação de acamamento/quebramento de plantas e diâmetro basal de colmos, no espaçamento de 0,90 metros, obteve-se maior porcentagem de AEQ e menor DC. Deve-se ao fato, de que em populações e espaçamentos maiores, haverá maior quantidade de plantas por metro linear, a qual favorece competições por nutrientes e principalmente de luz, ocorrendo assim um estiolamento da planta, ocasionando maior porcentagem de plantas acamadas e/ou quebradas em virtude colmos mais finos. Embora a porcentagem de acamamento mostrou-se baixa, variando de 1,16 a 2,47\% respectivamente com o aumento das populações de plantas, a quantidade de planta acamada e quebrada varia de 464 a 2.470 plantas nas populações de 40 a 100 mil plantas.

Em relação ao diâmetro basal de colmo, Brachtvogel (2008), ao comparar as formas de distribuição espacial de plantas equidistantes e o espaçamento de 0,80 metros na entrelinha, preconizado como o convencionalmente utilizado, em populações de 30, 45, 60, 75, 90, 105 mil plantas ha ${ }^{-1}$, constatou maior diâmetro do colmo, quando comparado ao espaçamento de menor equidistância, no caso de $0,45 \mathrm{~m}$ utilizado. $\mathrm{O}$ mesmo resultado foi verificado por Palhares (2003) que constatou aumento no diâmetro de colmo no menor espaçamento entre 
linhas, em altas populações, independente do genótipo utilizado no estudo, citando também menor diâmetro de colmo quando se reduz a população. Entretanto, também na analise de regressão, com o aumento da densidade populacional, houve uma diminuição do diâmetro médio basal do colmo das plantas em ambos os espaçamentos. No entanto, analisando o comportamento do espaçamento do hibrido DKB 390 dentro de populações, verifica-se pelo desdobramento, efeito significativo (Tabela 4) entre os espaçamentos nas populações, havendo uma tendência de que no espaçamento de $0,90 \mathrm{~m}$, pelo maior número de plantas por metro linear, houve maior porcentagem de acamamento e quebramento de plantas, por haver maior competição na linha de semeadura.

Tabela 3. Porcentagem de acamamento e quebramento de plantas (AEQ), altura média de plantas (AP), altura média de inserção de espiga principal (AIE) e diâmetro basal do colmo (DC), em função de sistema de cultivo, espaçamento e população de plantas. Selvíria-MS, Brasil (2010/2011).

\begin{tabular}{|c|c|c|c|c|c|}
\hline & & $\mathrm{AEQ}^{1}$ & $\mathbf{A P}$ & AIE & DC \\
\hline & & $(\%)$ & $(\mathrm{m})$ & $(\mathrm{m})$ & $(\mathrm{mm})$ \\
\hline $\begin{array}{c}\text { Sistema } \\
\text { de } \\
\text { cultivo } \\
\end{array}$ & $\begin{array}{l}\text { SPC } \\
\text { SPD }\end{array}$ & $\begin{array}{l}1,79 \\
1,95\end{array}$ & $\begin{array}{l}2,79 \\
2,81\end{array}$ & $\begin{array}{l}1,40 \\
1,36\end{array}$ & $\begin{array}{l}25,16 a \\
24,43 b\end{array}$ \\
\hline D.M.S (5\%) & & 0,25 & 3,02 & 3,16 & 0,68 \\
\hline Teste F & & 1,65 & 0,17 & $7,90 * *$ & $4,47 * *$ \\
\hline Espaçamento (m) & $\begin{array}{l}0,45 \\
0,90\end{array}$ & $\begin{array}{l}1,60 \mathrm{~b} \\
2,14 \mathrm{a}\end{array}$ & $\begin{array}{l}2,79 \\
2,80\end{array}$ & $\begin{array}{l}1,39 \\
1,37\end{array}$ & $\begin{array}{l}25,54 \mathrm{a} \\
24,04 \mathrm{~b}\end{array}$ \\
\hline $\begin{array}{c}\text { D.M.S }(5 \%) \\
\text { Teste F }\end{array}$ & & $\begin{array}{c}0,25 \\
17,37 * *\end{array}$ & $\begin{array}{c}3,02 \\
0,67 \mathrm{~ns}\end{array}$ & $\begin{array}{c}3,16 \\
1,82 \mathrm{~ns}\end{array}$ & $\begin{array}{c}0,69 \\
19,24 * *\end{array}$ \\
\hline $\begin{array}{c}\text { População } \\
\text { de } \\
\text { plantas }\left(h^{-1}\right)\end{array}$ & $\begin{array}{c}40.000 \\
55.000 \\
70.000 \\
85.000 \\
100.000\end{array}$ & $\begin{array}{c}1,16^{1,2} \\
1,07 \\
1,88 \\
2,56 \\
2,67\end{array}$ & $\begin{array}{l}2,69^{3} \\
2,77 \\
2,81 \\
2,85 \\
2,86\end{array}$ & $\begin{array}{l}1,27^{4} \\
1,36 \\
1,39 \\
1,44 \\
1,46\end{array}$ & $\begin{array}{l}28,30^{5} \\
26,33 \\
24,39 \\
23,17 \\
21,55\end{array}$ \\
\hline Teste F & & $28,97 * *$ & $17,36 * *$ & $16,40 * *$ & $45,32 * *$ \\
\hline $\begin{array}{c}\text { Teste F } \\
\text { (interação) }\end{array}$ & $\begin{array}{c}\text { SC x E } \\
\text { SC x POP } \\
\text { Ex POP } \\
\text { SC } \times \text { Ex POP }\end{array}$ & $\begin{array}{c}0,57 \\
0,26 \\
3,98 * * \\
0,046\end{array}$ & $\begin{array}{l}0,19 \\
0,33 \\
0,34 \\
1,38\end{array}$ & $\begin{array}{l}0,55 \\
0,43 \\
0,75 \\
1,60\end{array}$ & $\begin{array}{l}1,31 \\
1,61 \\
1,41 \\
0,36\end{array}$ \\
\hline $\begin{array}{c}\text { Media geral } \\
\text { CV }(\%)\end{array}$ & & $\begin{array}{c}1,86 \\
30,28\end{array}$ & $\begin{array}{l}2,80 \\
2,42\end{array}$ & $\begin{array}{l}1,38 \\
5,08\end{array}$ & $\begin{array}{c}24,79 \\
6,17\end{array}$ \\
\hline
\end{tabular}

Médias seguidas de mesma letra, não diferem pelo teste de Tukey a $5 \%$ de probabilidade. * $\mathrm{e}^{* *}$ Significativo a 5 e 1\%. ${ }^{1}$ SPC: sistema cultivo convencional; SPD: sistema cultivo direto. SC: sistema de cultivo; E: espaçamento; POP: população de plantas. Dados transformados em $\sqrt{ } \mathrm{x}+0,5:{ }^{1} \mathrm{y}=0,318+0,606 \mathrm{x}, \mathrm{R}^{2}=0,88$ $(45 \mathrm{~cm}) \mathrm{e}^{2} \mathrm{y}=0,714+0,30 \mathrm{x}, \mathrm{R}^{2}=0,93(90 \mathrm{~cm}){ }^{3} \mathrm{y}=2,60+0,000031 \mathrm{x}, \mathrm{R}^{2}=0,92 ;{ }^{4} \mathrm{y}=1,16+0,000029 \mathrm{x}, \mathrm{R}^{2}=$ 0,$95 ; y^{5}=32,52-0,00012 x, R^{2}=0,99$.

Cultura Agronômica, Ilha Solteira, v.24, n.1, p.27-44, 2015 
Tabela 4. Desdobramento da interação entre população e espaçamento de plantas para porcentagem de acamamento e quebramento de plantas na cultura do milho. Selviria-MS, Brasil (2010/2011).

\begin{tabular}{ccc}
\hline $\begin{array}{c}\text { Populações } \\
\text { (plantas ha) }\end{array}$ & $0,45 \mathrm{~m}$ & $0,90 \mathrm{~m}$ \\
\cline { 2 - 3 } 40.000 & $1,11 \mathrm{c} \mathrm{A}$ & $1,22 \mathrm{c} \mathrm{A}$ \\
55.000 & $1,09 \mathrm{c} \mathrm{A}$ & $1,04 \mathrm{c} \mathrm{A}$ \\
70.000 & $1,70 \mathrm{~b} \mathrm{~B}$ & $2,07 \mathrm{~b} \mathrm{~A}$ \\
85.000 & $1,92 \mathrm{~b} \mathrm{~B}$ & $3,16 \mathrm{a} \mathrm{A}$ \\
100.000 & $2,19 \mathrm{a} \mathrm{A}$ & $3,19 \mathrm{a} \mathrm{B}$ \\
\hline
\end{tabular}

Medias seguidas por mesma letra minúscula nas colunas e maiúscula nas linhas, não diferem pelo teste de Tukey em nível de $5 \%$ de probabilidade.

Analisando a Tabela 3, notou-se que houve ajuste significativo de regressões lineares com aumento de AEQ, AP, AIE e DC de plantas com a elevação da densidade populacional na linha de semeadura. Entretanto com o aumento da densidade de semeadura, o diâmetro basal de colmo mostrou efeito de regressão com decréscimo linear, sendo explicado pelo estiolamento das plantas pela competição na linha de semeadura. Pelos dados obtidos por Kunz (2005), que obteve diferenças para a altura média de plantas e de inserção da espiga entre híbridos, sendo independentemente do espaçamento e da população de plantas adotadas, o autor atribuiu tal fato ao fator genético. Neste experimento, como foi analisado apenas um único hibrido, supõe-se que suas características não sejam influenciadas, sobretudo pela avaliação de altura de plantas e espigas, pelos sistemas de cultivos e espaçamentos de 0,90 e 0,45 metros, mas sim pelo fato de haver competição intraespecífica na linha e entrelinha de semeadura, embora constatado efeito significativo para sistema de cultivo para DC. Da mesma forma, Brachtvogel (2008) verificou que o fator arranjo espacial não influenciou a altura de inserção de espiga, ao contrário do fator população, pois à medida que se aumentou a população de plantas ha $^{-1}$, resultou em maior altura de plantas, com padrão de crescimento quadrático. Na Tabela 5 constam os dados de diâmetro médio de espiga, sabugo, comprimento médio da espiga, comprimento médio de grãos e número de fileiras de grãos por espiga.

Os resultados evidenciaram que o diâmetro da espiga e sabugo, diferiu entre o SPC e SPD, sendo maior DE e DS no sistema convencional (SPC). Para os componentes de CE, CG e NFG, não foram verificadas diferenças significativas em relação sistema de cultivo. Nos espaçamentos adotados, não foram verificadas diferenças significativas para DE, DS, CE, CG e NFG. Contudo, na analise de regressão para as populações, houve efeito significativo em menor diâmetro de espigas, consequentemente, menor diâmetro de sabugo, menor comprimento de espiga e menor comprimento de grãos com ajuste linear decrescente com o aumento das populações estabelecidas. De um modo geral, com o aumento da população, o diâmetro da espiga decresceu, o que corrobora com os resultados encontrados por Lenzi (1992).

Segundo Kappes (2010), o aumento da população provocou redução linear do diâmetro da espiga em todos os híbridos que testou em seu experimento, concordando com 
os resultados observados por Lenzi (1992), Brachtvogel (2008) e Marchão et al. (2005). No entanto, Vieira et al. (2010) constataram redução linear no diâmetro de espiga com o aumento da população de plantas para os genótipos Penta e 30P34, enquanto que os genótipos DKB 214 e SWB 551 apresentaram redução quadrática. Em relação ao diâmetro de sabugo, não houve efeito pelo espaçamento entre linhas e não houve interação entre os fatores isolados, entretanto, houve comportamento similar ao diâmetro de espiga na analise de regressão.

Tabela 5. Diâmetro médio de colmo (DE), diâmetro médio de sabugo (DS), comprimento médio de espiga (CE) e comprimento médio de grãos $(\mathrm{CG})$ e número de fileiras de grãos por espiga (NFG), em função de sistema de cultivo, espaçamento e população de plantas. Selvíria-MS, Brasil (2010/2011).

\begin{tabular}{ccccccc}
\hline & & DE & DS & CE & CG & NFG \\
\hline & & $(\mathrm{mm})$ & $(\mathrm{mm})$ & $(\mathrm{cm})$ & $(\mathrm{mm})$ & (por espiga) \\
Sistema de & SPC & $52,21 \mathrm{a}$ & $31,77 \mathrm{a}$ & 19,05 & 10,51 & 16,00 \\
cultivo & SPD & $50,92 \mathrm{~b}$ & $30,18 \mathrm{~b}$ & 18,72 & 10,05 & 16,20 \\
\hline D.M.S (5\%) & & 0,82 & 0,36 & 0,37 & 0,59 & 0,34 \\
Teste F & & $9,90 * *$ & $5,06^{* *}$ & $3,20 \mathrm{~ns}$ & $1,28 \mathrm{~ns}$ & $2,11 \mathrm{~ns}$ \\
\hline Espaçamento & 0,45 & 51,58 & 30,81 & 18,92 & 10,40 & 16,10 \\
(m) & 0,90 & 51,55 & 31,14 & 18,85 & 10.16 & 16,12 \\
\hline D.M.S (5\%) & & 0,81 & 0,36 & 0,37 & 0,59 & 0,34 \\
Teste F & & 0,006 & 3,37 & 0,16 & 1,49 & 0,03 \\
\hline & 40.000 & $53,52^{1}$ & $32,24^{2}$ & $20,56^{3}$ & $10,64^{4}$ & 16,22 \\
População de & 55.000 & 53,11 & 31,79 & 19,91 & 10,68 & 16,35 \\
plantas (ha-1) & 70.000 & 51,05 & 30,82 & 18,69 & 9,97 & 16,32 \\
& 85.000 & 50,81 & 30,21 & 18,07 & 10,28 & 15,82 \\
& 100.000 & 49,36 & 29,81 & 17,19 & 9,83 & 15,85 \\
\hline Teste F & & $14,28^{*}$ & $25,78^{* *}$ & $42,22^{* *}$ & $2,98 *$ & 1,83 \\
\hline Teste F & SC x E & 1,41 & 1,49 & 2,32 & 0,44 & 0,12 \\
(interação) & SC x POP & 0,57 & 0,37 & 2,41 & 1,38 & 2,18 \\
& SC POP & 0,27 & 1,56 & 2,30 & 0,16 & 0,38 \\
\hline Media geral & & 51,57 & 30,97 & 18,88 & 10,28 & 16,12 \\
CV (\%) & & 3,54 & 2,62 & 4,44 & 8,61 & 4,71 \\
\hline P & & 1,87 & 2,52 & 2,61 & 0,77 & 1,36 \\
\hline
\end{tabular}

Médias seguidas de mesma letra, não diferem entre si, pelo teste de Tukey a 5\% de probabilidade. * e ** significativo a $1 \%$ e $5 \%$ de probabilidade pelo teste F. SPC: sistema cultivo convencional; SPD: sistema cultivo direto. SC: sistema de cultivo; E: espaçamento; POP: população de plantas. ${ }^{1} \mathrm{y}=56,52-0,000071 \mathrm{x}, \mathrm{R}^{2}$ $=0,94 ;{ }^{2} \mathrm{y}=33,76-0,000038 \mathrm{x}, \mathrm{R}^{2}=0,85 ;{ }^{3} \mathrm{y}=22,43-0,000051 \mathrm{x}, \mathrm{R}^{2}=0,91 ;{ }^{4} \mathrm{y}=11,22-0,000013 \mathrm{x}, \mathrm{R}^{2}=$ 0,70 .

Em relação ao comprimento da espiga, fica evidente a progressiva redução no comprimento em função do aumento da população, mas não foi verificado efeito do espaçamento para este componente. Contrariamente, Dourado Neto et al. (2003) verificaram

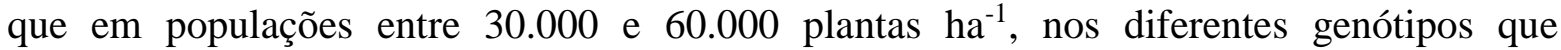

Cultura Agronômica, Ilha Solteira, v.24, n.1, p.27-44, 2015 
avaliaram, houve aumento do comprimento das espigas pela redução do espaçamento de 0,80 para 0,40 m para populações maiores de 65.000 plantas ha $^{-1}$.

De acordo com Kappes (2010) ao avaliar desempenho de híbridos em dois espaçamentos entrelinhas (0,45 e 0,90 m), verificou que o hibrido AG 9010, não foi alterado quanto ao comprimento de grão pela alteração do espaçamento, mas sim pelo acréscimo populacional, diminuindo assim o comprimento dos grãos. O que corroborou com este experimento em relação a este atributo. Desta forma, para efeito de ajuste linear decrescente, o comprimento de grãos segue o comportamento do diâmetro de sabugo e diâmetro de espiga. Em fileiras de grãos por espiga, não houve efeito do sistema de cultivo e espaçamento adotado, tampouco houve ajuste de regressão. Contrariamente, Palhares (2003) obteve aumento significativo do número de fileiras de grãos por espiga para o hibrido DKB 911 quando da redução do espaçamento de 80 para $40 \mathrm{~cm}$ entre as linhas sob a população de 30.000 plantas ha-1 ${ }^{-1}$ e também para o AG 1051 na população de 60.000 plantas ha- ${ }^{-1}$. Este último teve seu número de fileiras reduzido na combinação de $40 \mathrm{~cm}$ com 90.000 plantas ha 1. Na Tabela 6, em relação à massa de cem grãos (M100G), prolificidade de grãos (PROLIF) e produtividade de grãos (PROD), observou-se que não houve efeito significativo para M100G e PROLIF em relação ao sistema de cultivo, enquanto que não houve diferença em relação ao espaçamento para produtividade de grãos (PROD). Contudo observou-se efeito significativo para o sistema de cultivo sobre a produtividade de grãos (PROD), com maior produção de grãos em sistema de cultivo convencional.

Em relação à massa de 100 grãos, relatos semelhantes foram observados por Andrade; Otegui e Vega (2000), Borrás e Otegui (2001) e Sangoi et al. (2002), em que a massa de grãos é o componente de produção menos alterado por variações nas práticas de manejo. No entanto apresentou ajuste de regressão linear decrescente com o aumento da população, contrariamente aos resultados apresentado neste estudo. Pereira et al. (2008), em estudo realizado na Universidade Federal de Alagoas CECA/UFAL, utilizando os híbridos de milho FORT e AGN 30A00, nos espaçamentos 0,80 e $0,40 \mathrm{~m}$ e submetidos às populações de 60.000 e 70.000 plantas ha $^{-1}$, a maior densidade de plantas também não alterou a massa de 100 grãos e nenhum outro componente de produção do híbrido AGN 30A00, cultivado no mesmo espaçamento, provavelmente em virtude deste híbrido apresentar arquitetura com folhas mais eretas e menor área foliar, minimizando a competição entre plantas (ALMEIDA et al., 2000).

Entretanto, muitos autores obtiveram resultados diferentes em relação à massa de 100 grãs com resultados que diferem entre híbridos. Marchão et al (2005), avaliando o comportamento de híbridos de milho (A 2555, A 2288, AG 9010, AG 6690, P30F88 e Valent), cultivados em densidades populacionais $(40,53,71,84$ e 97 mil plantas por hectare) e sob espaçamento reduzido $(0,45 \mathrm{~m})$, observaram que para todos os híbridos testados, houve decréscimo na massa de grãos a medida que a densidade de milho aumentou de 40 para 97 mil plantas por hectares. Consequentemente, houve um incremento da esterilidade das plantas e um decréscimo do número de grãos por espiga e, também, da massa dos grãos, sendo resultante da redução no crescimento dos grãos, notadamente na parte superior da espiga, que, muitas vezes, não se desenvolvem, ainda que tenha havido 
fertilização regular dos óvulos (MARCHÃO et al., 2006).

Tabela 6. Massa de 100 grãos (M100G), Prolificidade de espiga (PROLIF) e Produtividade de grãos (PROD), em função de sistema de cultivo, espaçamento e população de plantas. Selvíria-MS, Brasil (2010/2011).

\begin{tabular}{|c|c|c|c|c|}
\hline & & M100G & PROLIF & PROD \\
\hline \multirow{3}{*}{$\begin{array}{l}\text { Sistema de } \\
\text { cultivo }\end{array}$} & & (g) & (Espiga. Planta) & $\left(\mathrm{kg} \mathrm{ha}^{-1}\right)$ \\
\hline & $\mathrm{SPC}$ & 34,46 & 1,04 & $9.761 \mathrm{a}$ \\
\hline & SPD & 35,73 & 1,06 & $8.180 b$ \\
\hline \multirow{2}{*}{$\begin{array}{c}\text { D.M.S }(5 \%) \\
\text { Teste F } \\
\end{array}$} & & 1,38 & 0,02 & 657 \\
\hline & & $3,40 \mathrm{~ns}$ & $2,75 \mathrm{~ns}$ & $23,17 * *$ \\
\hline \multirow{2}{*}{ Espaçamento (m) } & 0,45 & 34,55 & 1,04 & 8.945 \\
\hline & 0,90 & 35,65 & 1,05 & 8.997 \\
\hline \multirow{2}{*}{$\begin{array}{c}\text { D.M.S }(5 \%) \\
\text { Teste F }\end{array}$} & & 1,38 & 0,02 & 657 \\
\hline & & 2,51 & 0,67 & 0,02 \\
\hline \multirow{5}{*}{$\begin{array}{l}\text { População de } \\
\text { plantas }\left(\mathbf{h a}^{-1}\right)\end{array}$} & 40.000 & $35,76^{1}$ & $1,13^{2}$ & $6.885^{3}$ \\
\hline & 55.000 & 36,37 & 1,07 & 8.014 \\
\hline & 70.000 & 35,29 & 1,02 & 9.640 \\
\hline & 85.000 & 34,44 & 1,01 & 9.906 \\
\hline & 100.000 & 33,63 & 1,01 & 10.410 \\
\hline Teste F & & $2,96 *$ & $17,95 * *$ & $16,06 * *$ \\
\hline \multirow{4}{*}{$\begin{array}{c}\text { Teste F } \\
\text { (interação) }\end{array}$} & $\mathrm{SC} \times \mathrm{E}$ & 2,86 & 1,08 & 3,95 \\
\hline & SC x POP & 0,87 & 0,08 & 0,99 \\
\hline & E x POP & 1,80 & 1,37 & 0,65 \\
\hline & $\mathrm{SC} \times \mathrm{E} \times \mathrm{POP}$ & 0,85 & 0,19 & 0,915 \\
\hline \multirow{2}{*}{$\begin{array}{c}\text { Media geral } \\
\mathrm{CV}(\%)\end{array}$} & & 35,01 & 1,05 & 8.971 \\
\hline & & 8,02 & 4,79 & 1637 \\
\hline
\end{tabular}

Médias seguidas de mesma letra, não diferem entre si, pelo teste de Tukey a 5\% de probabilidade. * $\mathrm{e}^{* *}$ significativo a $5 \%$ e $1 \%$ de probabilidade pelo teste F. SPC: sistema cultivo convencional; SPD: sistema cultivo direto. SC: sistema de cultivo; E: espaçamento; POP: população de plantas. ${ }^{1} \mathrm{y}=37,96-0,00048 \mathrm{x}, \mathbf{R}^{2}=$ 0,$92 ;{ }^{2} \mathrm{y}=1,19-0,00026 \mathrm{x}, \mathrm{R}^{2}=0,85 ;{ }^{3} \mathrm{y}=4.748,00+0,0057 \mathrm{x}, \mathrm{R}^{2}=0,92$.

Em relação à prolificidade, não houve diferença estatística para manejo adotado, espaçamento e interação entre os fatores. Porém houve efeito significativo para regressão nas populações testadas, aumentado o número de espigas por planta com menor adoção de menor população de plantas. Kappes (2010) também não observou alterações da prolificidade com a redução do espaçamento. Isso evidencia que esta característica de produção é dependente da genética do hibrido.

No presente experimento, a produtividade de grãos foi maior em cultivo convencional em relação ao direto. Um dos fatores inerentes ao plantio convencional ser maior que o direto, é a presença de compactação do solo. Os diferentes mecanismos de mobilização do solo alteram sua estrutura e seus atributos físicos, em virtude do grau e intensidade de mobilização (SHAFFER e JOHNSON, 1982). No sistema plantio direto, a movimentação do solo é restrita à linha de semeadura, mas a ocorrência sistemática do tráfego causa

Cultura Agronômica, Ilha Solteira, v.24, n.1, p.27-44, 2015 
compactação na superfície do solo.

Bergamaschi et al. (2004) ressaltaram um outro fator importante em que plantas sob plantio direto podem apresentam um arquitetura foliar mais compactada, com folhas mais eretas, o que permite maior transmissividade de RFA (radiação fotossinteticamente ativa) para o solo. E as plantas em preparo convencional, caracterizam-se por apresentar arquitetura foliar mais aberta, com folhas tendendo a planiforme e desta forma, ocupando maior espaço interceptando maior quantidade de RFA, atribuindo esse fato pela melhor condição nutricional de solo em preparo convencional, podendo haver maior disponibilidade de nitrogênio às plantas neste sistema comparado ao plantio direto (BERGAMASCHI, 2004).

Em relação à produtividade de grãos, seu aumento, por meio da redução no espaçamento entre fileiras, já é demostrada por diversos autores (ARGENTA, et al. 2001; JOHNSON et al. 1998; OTTMAN e WELCH, 1989), devido a melhor distribuição de plantas na linha e na variabilidade entre plantas, sendo uma prática importante para maximizar a interceptação da radiação solar e otimizar seu uso. Entretanto, no presente experimento não foi detectada diferença significativa nos espaçamentos de 0,45 e 0,90 m. Resultado semelhante foi verificado por Kappes (2010), onde a redução do espaçamento de 0,90 para $0,45 \mathrm{~m}$ entre as linhas não proporcionou aumento na produtividade de grãos para os híbridos XB 6010, XB 6012, XB 7253 e XB 9003, demonstrando que essa variação no espaçamento não se manifestou pela capacidade das plantas em interceptar a luz. (BALLARÉ; SCOPEL; SÁNCHEZ, 1995).

Brachtvogel (2008) ao analisar a produtividade de grãos em relação às densidades populacionais, para o milho hibrido 2B587, não foi possível ajustar modelos de regressão linear, mas no modelo quadrático, houve produtividade com produção máxima estimada com população entre 60.000 e 75.000 plantas ha-1 . Marchão et al., (2006) verificaram em experimento com densidades populacionais de milho, que o hibrido AG 9010, um híbrido simples, semiprecoce, e com arquitetura foliar ereta, foi o que alcançou as melhores médias de produtividade com comportamento linear, demonstrando melhor adaptação à densidade acima de 85 mil plantas ha ${ }^{-1}$, que os demais híbridos analisados. Esse resultado corrobora com diversos trabalhos que mostram que os híbridos simples são mais indicados ao cultivo adensado (MEROTTO JUNIOR. et al., 1997; ARGENTA et al., 2001; SANGOI et al., 2002a; DOURADO-NETO et al., 2003; RESENDE et al., 2003).

No entanto, tradicionalmente na região dos Cerrados, o melhoramento genético prima por selecionar híbridos para regiões de chapada, com altitudes acima de $900 \mathrm{~m} \mathrm{e}$ temperaturas mais amenas durante a noite, o que não é o caso do local estudado. O híbrido DKB 390 sendo hibrido simples, apresentou comportamento linear de resposta da produtividade ao incremento da população. Nas condições em que se avaliou a atenuação da radiação ao longo do dossel, observou-se um comportamento diferencial da interceptação da radiação em função da densidade de semeadura utilizada, em espaçamento de 0,45 m entre linhas, onde houve maior radiação interceptada, porém para a produtividade de grãos isso não se transferiu em diferença estatística para aumento da produtividade. 


\section{CONCLUSÕES}

Em relação ao comportamento e características do hibrido de milho DKB 390 testado, sugere-se que, quanto maior a população de plantas por hectare, maior foi o incremento na produtividade de grãos. À medida que aumentou a população de plantas, independente do espaçamento de 0,45 e 0,90 metros, houve um decréscimo do: diâmetro basal de colmo, diâmetro médio da espiga, sabugo, comprimento da espiga e comprimento de grãos.

O espaçamento de 0,45 ou $0,90 \mathrm{~m}$ entrelinhas não alterou os componentes de produção e produtividade do milho em cultivo de primavera/verão no cerrado independente da população de plantas.

No sistema de cultivo convencional (SPC), verificou-se maior produtividade de grãos em relação ao plantio direto, pelo fato de que há maior disponibilidade momentânea pelo revolvimento do solo de nitrogênio nas fases iniciais do desenvolvimento da planta.

\section{REFERÊNCIAS BIBLIOGRÁFICAS}

ALMEIDA, M. L.; MEROTTO JÚNIOR, A.; SANGOI, L.; ENDER, M.; GUIDOLIN, A. F. Incremento na densidade de plantas: uma alternativa para aumentar o rendimento de grãos de milho em regiões de curta estação estival de crescimento. Ciência Rural, Santa Maria, v. 30, n. 1, p.23-29, 2000.

ALVAREZ, C. G. D.; VON PINHO, R. G.; BORGES, I. D. Avaliação de características agronômicas e de produção de forragem e grãos de milho em diferentes densidades de semeadura e espaçamentos entre linhas. Ciência e Agrotecnologia, Lavras, v. 30, n. 3, p.402-408, 2006.

ANDRADE, F. H.; OTEGUI, M. E.; VEGA, C. Intercepted radiation at flowering and kernel number in maize. Agronomy Journal, Madison, v. 92, n. 1, p.92-97, 2000.

ARGENTA, G.; SANGOI, L.; SILVA, P. R. F.; RAMPAZZO, C.; GRACIETTI, L. C.; STRIEDER, M. L.; FORSTHOFER, E. L.; SUHRE, E. Potencial de rendimento de grãos de milho em dois ambientes e cinco sistemas de produção. Scientia Agraria, Curitiba, v. 4, n. 1/2, p.27-34, 2003.

ARGENTA, G.; SILVA, P. R. F.; BORTOLINI, C. G.; FORSTHOFER, E. L.; MANJABOSCO, E. A.; BEHEREGARAY NETO, V. Resposta de híbridos simples de milho à redução do espaçamento entre linhas. Pesquisa Agropecuária Brasileira, Brasília, v. 36, n. 1, p.71-78, 2001.

BALLARÉ, C. L.; SCOPEL, A. L.; SÁNCHEZ, R. A. Plant photomorphogenesis in canopies, crop growth, and yield. HortScience, Nashville, v. 30, n. 6, p.1172-1181, 1995.

Cultura Agronômica, Ilha Solteira, v.24, n.1, p.27-44, 2015 
BORRÁS, L.; OTEGUI, M. E. Maize kernel weight response to postflowering sourcesink ratio. Crop Science, Madison, v. 41, n. 6, p.1816-1822, 2001.

BRACHTVOGEL, E. L. Densidades e arranjos populacionais de milho e componentes agronômicos. 2008. 96 f. Dissertação (Mestrado em Agronomia - Energia na Agricultura) Faculdade de Ciências Agronômicas, Universidade Estadual Paulista, Botucatu, 2008.

BERGAMASCHI, H.; DALMAGO, G. A.; BERGONCI, J. I.; BIANCHI, C. A. M.; MÜlLER, A. G.; COMIRAN, F.; HECKLER, B. M. M. Distribuição hídrica no período crítico do milho e produção de grãos. Pesquisa Agropecuária Brasileira, v.39, p.831-839, 2004.

BULLOCK, D. G.; NIELSEN, R. L.; NYQUIST, W. E. A growth analysis comparison of corn grown in conventional and equidistant plant spacing. Crop Science, Madison, v. 28, n. 2, p.254-258, 1988.

CARVALHO, I. Q. Espaçamento entre fileiras e população de plantas em milho. 2007.118 f. Dissertação (Mestrado em Agronomia) - Universidade Estadual de Ponta Grossa, Ponta Grossa, 2007. Disponível em: 〈http://www.ciiagro.sp.gov.br〉. Acesso em: 05 set. 2011.

DOURADO NETO, D.; PALHARES, M.; VIEIRA, P. A.; MANFRON, P. A.; MEDEIROS, S. L. P.; ROMANO, M. R. Efeito da população de plantas e do espaçamento sobre a produtividade de milho. Revista Brasileira de Milho e Sorgo, Sete Lagoas, v. 2, n. 3, p.63$77,2003$.

FANCELli, A. L.; DOURADO NETO, D. Produção de milho. 2. ed. Guaíba: Agropecuária, 2004. v.1. 360 p.

FANCELli, A. L.; DOURADO NETO, D. Produção de milho. 1. ed. Guaíba: Agropecuária, 2000. v.1. 360 p.

FERREIRA, D. F. Análises estatísticas por meio do Sisvar para Windows versão 4.0. In: REUNIÃO ANUAL DA REGIÃO BRASILEIRA DA SOCIEDADE INTERNACIONAL DE BIOMETRIA, 45, 2000, São Carlos. Anais... São Carlos: UFSCar, 2000. p. 255-258.

FLÉNET, F.; KINIRY, J. R.; BOARD, J. E.; WESTGATE, M. E.; REICOSKY, D. C. Row spacing effects on light extinction coefficients of corn, sorghum, soybean, and sunflower. Agronomy Journal, Madison, v. 88, n. 2, p.185-190, 1996. 
FORSTHOFER, E. L. Potencial de rendimento de grãos e desempenho econômico do milho em cinco níveis de manejo, em três épocas de semeadura. 2004. 94 f. Dissertação (Mestrado em Fitotecnia) - Universidade Federal do Rio Grande do Sul, Porto Alegre, 2004.

JOHNSON, G. A.; HOVERSTAD, T. R.; GREENWALD, R. E. Integrated weed management using narrow corn row spacing, herbicides, and cultivation. Agronomy Journal, Madison, v. 90, n.1, p.40-46, 1998.

KAPPES. C. Desempenho de híbridos de milho em diferentes arranjos espaciais de plantas. 2010. 127 f. Dissertação (Mestrado em Agronomia - Sistema de Produção) Faculdade de Engenharia, Universidade Estadual Paulista "Júlio de Mesquita Filho", Ilha Solteira, 2010.

KUNZ, R. P. Influência do arranjo de plantas e da população em características agronômicas e produtividade do milho. 2005. 115 f. Dissertação (Mestrado em Produção Vegetal) - Universidade Estadual de Ponta Grossa, Ponta Grossa, 2005.

LENZI, E. A. População e distribuição espacial de plantas em cultura de milho (Zea mays L.). 1992. 106 f. Tese (Doutorado em Agronomia - Agricultura) - Faculdade de Ciências Agronômicas, Universidade Estadual Paulista "Júlio de Mesquita Filho", Botucatu, 1992.

MADDONNI, G. A.; OTEGUI, M. E.; CIRILO, A. G. Plant population density, row spacing and hybrid effects on maize canopy architecture and light attenuation. Field Crops Research, Amsterdam, v. 71, n. 3, p.183-193, 2001.

MATOS, M. J. L. F.; TAVARES, S. A.; SANTOS, F. F. DOS; MELO. M. F. DE; LANA,M.M. Milho verde. 2006. Disponível em: <http://www.cnph.embrapa.br/paginas/dicas_ao_consumidor/milho_verde.htm>. Acesso em: 03 out. 2011.

MARCHÃO, R. L.; BRASIL, E. M.; XIMENES, P.A. Interceptação da radiação fotossinteticamente ativa e rendimento de grãos do milho adensado. Revista Brasileira de Milho e Sorgo, Goiania, v. 5, n. 6, p.170-181, 2006.

MARCHÃO, R. L. et al. Densidade de plantas e características agronômicas de híbridos de milho sob espaçamento reduzido entre linhas. Pesquisa Agropecuária Tropical, Goiânia, v. 35, n. 2, p.93-101, 2005.

MEROTTO JÚNIOR, A.; ALMEIDA, M. L.; FUCHS, O. Aumento no rendimento de grãos de milho através do aumento da população de plantas. Ciência Rural, Santa Maria, v. 27, n. 4, p.549-554, 1997.

Cultura Agronômica, Ilha Solteira, v.24, n.1, p.27-44, 2015 
MURPHY, S. D.; YAKUBU, Y.; WEISE, S. F.; SWANTON, C. J. Effects of planting pattern and inter-row cultivation on competition between corn (Zea mays) and late emerging weeds. Weed Science, Georgia, v. 44, p.856-870, 1996.

NUMMER FILHO, I.; HENTSCHKE, C. W. Redução do espaçamento entre linhas na cultura do milho. Revista Plantio Direto, Passo Fundo, v.8, n. 92, p.1-5, 2006.

OTTMAN, M. J., WELCH, L. F. Planting patterns and radiation interception, plant nutrient concentration, and yield in corn. Agronomy Journal, Madison, v. 81, n. 2, p.167-174, 1989.

PAES, J. M. V.; ZITO, R. K. Manejo de plantas daninhas na cultura do milho. Informe Agropecuário, Belo Horizonte, v. 27, n. 233, p.54-64, 2006.

PALHARES, M. Distribuição e população de plantas e produtividade de grãos de milho. 2003. 90 f. Dissertação (Mestrado em Agronomia - Fitotecnia) - Escola Superior de Agricultura "Luiz de Queiroz"- Universidade de São Paulo, Piracicaba, 2003.

PEREIRA, F. R. S.; CRUZ, S. C. S.; ALBUQUERQUE, A. W.; SANTOS, J. R.; SILVA, E. Arranjo espacial de plantas de milho em sistema plantio direto. Revista Brasileira de Engenharia Agrícola e Ambiental, Campina Grande, v. 12, n. 1, p.69-74, 2008.

RAIJ, B. van; CANTAREllA, H.; QUAGGIO, J. A.; FURLANI, A. M. C. Recomendações de adubação e calagem para o Estado de São Paulo. 2. ed. Campinas: Instituto Agronômico, 1996. 285 p. (Boletim Técnico, 100).

RESENDE, S. G.; VON PINHO, R. G.; VASCONCELOS, R. C. Influência do espaçamento entre linhas e da densidade de plantio no desempenho de cultivares de milho. Revista Brasileira de Milho e Sorgo, Sete Lagoas, v. 2, n. 3, p.34-42, 2003.

SANGOI, L; SILVA, P. R. F. Densidade e arranjo populacional em milho. In: SEMINÁRIO NACIONAL DE MILHO SAFRINHA, 8., 2005, Assis. Anais... Campinas: Instituto Agronômico, 2005. p. 27-41.

SANGOI, L.; ARGENTA, G.; SILVA, P. R. F.; MINETTO, T. J.; BISOTTO, V. Níveis de manejo na cultura do milho em dois ambientes contrastantes: análise técnico-econômica. Ciência Rural, v. 33, n. 6, p.1021-1029, 2003.

SANGOI, L.; ALMEIDA, M. L.; GRACIETTI, M. A.; BIANCHET, P. Sustentabilidade do colmo em híbridos de milho de diferentes épocas de cultivo em função da densidade de plantas. Revista de Ciências Agroveterinárias, Lages, v. 1, n. 2, p.60-66, 2002. 
SHIOGA, P. S. Redução de espaçamento em milho safrinha. In: SEMINÁRIO NACIONAL DE MILHO SAFRINHA, 8., 2005, Assis. Anais... Campinas: Instituto Agronômico, 2005. p. 43-56.

SILVA, A.K. Redução do espaçamento entrelinhas na cultura do milho. In: REUNIÃO TÉCNICA CATARINENSE DE MILHO e FEIJÃO, 5., 2005, Chapecó. Resumos expandidos... Chapecó: Epagri/Cepaf, 2005. p. 27-30.

SHAFFER, R. L.; JOHNSON, C. E. Changing soil condition: The dynamic of tillage. In: PREDICTING TILLAGE EFFECTS ON SOIL PHYSICAL PROPERTIES AND PROCESSES. Proceedings. Madison, American Society of Agronomy, 1982. p.151-178.

SCHEEREN, B. R.; BAZONI, R.; BONO, J. A.; ARIAS, S. S.; OLIVEIRA, R.; SALOMÃO, L. Arranjo populacional para a cultura do milho na região central do Estado de Mato Grosso do Sul. Acta Scientiarum: Agronomy, Maringa, v. 26, n. 2, p.55-60, 2004.

TEASDALE, J. R. Influence of narrow row/high population corn (Zea mays) on weed control and light transmittance. Weed Technology, Lawrence, v. 9, n. 1, p.113-118, 1995.

VIEIRA, M. A.; CAMARGO, M. K.; DAROS, E.; ZAGONEL, J.; KOEHLER, H. S. Cultivares de milho e população de plantas que afetam a produtividade de espigas verdes. Acta Scientiarum. Agronomy, Maringá, v. 32, n. 1, p.81-86, 2010.

VILARINHO, A. A. Densidade e espaçamento como fatores de produtividade na cultura do milho. 2005. Disponível em: <http://www.agronline.com.br/artigos/artigo.php?id=237>. Acesso em: 12 dez. 2009.

Cultura Agronômica, Ilha Solteira, v.24, n.1, p.27-44, 2015 
